\title{
openheart Haemodynamic outcomes following aortic valve-in-valve procedure
}

\author{
Anne-Sophie Zenses, ${ }^{1,2}$ Abdellaziz Dahou, ${ }^{1}$ Erwan Salaun, ${ }^{1}$ Marie-Annick Clavel, ${ }^{1}$ \\ Josep Rodés-Cabau, ${ }^{1}$ Géraldine Ong, ${ }^{1}$ Ezéquiel Guzzetti, ${ }^{1}$ Mélanie Côté, ${ }^{1}$ \\ Robert De Larochellière, ${ }^{1}$ Jean-Michel Paradis, ${ }^{1}$ Daniel Doyle, ${ }^{1}$ \\ Siamak Mohammadi, ${ }^{1}$ Éric Dumont, ${ }^{1}$ Chekrallah Chamandi, ${ }^{1}$ \\ Tania Rodriguez-Gabella, ${ }^{1}$ Régis Rieu, ${ }^{2}$ Philippe Pibarot ${ }^{1}$
}

\begin{abstract}
- Additional material is published online only. To view please visit the journal online (http://dx.doi.org/10.1136/ openhrt-2018-000854).
\end{abstract}

To cite: Zenses A-S, Dahou A, Salaun E, et al. Haemodynamic outcomes following aortic valvein-valve procedure. Open Heart 2018;5:e000854. doi:10.1136/ openhrt-2018-000854

Received 11 May 2018 Revised 24 May 2018 Accepted 13 June 2018

Check for updates

(C) Author(s) (or their employer(s)) 2018. Re-use permitted under CC BY-NC. No commercial re-use. See rights and permissions. Published by BMJ.

${ }^{1}$ Quebec Heart and Lung Institute, Laval University, Quebec, Canada ${ }^{2}$ IFSTTAR, LBA UMR T24, AixMarseille Univ, Marseille, France

Correspondence to Dr Philippe Pibarot; philippe. pibarot@med.ulaval.ca

\section{ABSTRACT}

Background and objectives Transcatheter aortic valvein-valve implantation (ViV) has emerged as a valuable technique to treat failed surgical bioprostheses (BPs) in patients with high risk for redo surgical aortic valve replacement (SAVR). Small BP size $(\leq 21 \mathrm{~mm})$, stenotic pattern of degeneration and pre-existing prosthesispatient mismatch (PPM) have been associated with worse clinical outcomes after ViV. However, no study has evaluated the actual haemodynamic benefit associated with ViV. This study aims to compare haemodynamic status observed at post-ViV, pre-ViV and early after initial SAVR and to determine the factors associated with worse haemodynamic outcomes following ViV, including the rates of high residual gradient and 'haemodynamic futility'. Methods Early post-SAVR, pre-ViV and post-ViV echocardiographic data of 79 consecutive patients who underwent aortic ViV at our institution were retrospectively analysed. The primary study endpoint was suboptimal valve haemodynamics (SVH) following ViV defined by the Valve Academic Research Consortium 2 as the presence of high residual aortic mean gradient $(\geq 20 \mathrm{~mm} \mathrm{Hg}$ ) and/or at least moderate aortic regurgitation (AR). Haemodynamic futility of ViV was defined as $<10 \mathrm{~mm} \mathrm{Hg}$ decrease in mean aortic gradient and no improvement in AR compared with pre-Viv.

Results SVH was found in $61 \%$ of patients $(57 \%$ high residual gradient, $4 \%$ moderate $A R$ ) after ViV versus $24 \%$ early after SAVR. Pre-existing PPM and BP mode of failure by stenosis were independently associated with the primary endpoint (OR: $2.87 ; 95 \% \mathrm{Cl} 1.08$ to 7.65 ; $\mathrm{p}=0.035$ and OR: $3.02 ; 95 \% \mathrm{Cl} 1.08$ to $8.42 ; \mathrm{p}=0.035$, respectively) and with the presence of high residual gradient (OR: $4.38 ; 95 \% \mathrm{Cl} 1.55$ to $12.37 ; \mathrm{p}=0.005$ and OR: $5.37 ; 95 \% \mathrm{Cl} 1.77$ to $16.30 ; p=0.003$, respectively) following ViV. Criteria of ViV haemodynamic futility were met in $7.6 \%$ overall and more frequently in patients with pre-existing PPM and stenotic BP (18.5\%) compared with other patients $(2.0 \%)$. ViV restored haemodynamic function to early post-SAVR level in only $34 \%$ of patients.

Conclusion Although ViV was associated with significant haemodynamic improvement compared with pre-ViV in $>90 \%$ of patients, more than half harboured SVH outcome. Furthermore, only one-third of patients had a restoration of valve haemodynamic function to the early post-SAVR level. Pre-existing PPM and stenosis pattern of BP degeneration were the main factors associated with $\mathrm{SVH}$ and

\section{Key questions}

What is already known about this subject?

- Transcatheter aortic valve-in-valve implantation (ViV) is a valuable alternative to redo surgery for the treatment of failed bioprosthesis (BP) in patients with high surgical risk. However, high residual gradient is frequent following ViV and is associated with worse outcomes.

What does this study add?

- This is the first study to assess the valve haemodynamic benefit of ViV compared with pre-ViV status and also the degree of restoration of valve haemodynamic function compared with that achieved by initial surgical aortic valve replacement (SAVR). ViV improved significantly the valve haemodynamic status compared with pre-ViV in $92 \%$ of patients and was 'haemodynamically futile' in only $8 \%$. However, aortic valve haemodynamics was suboptimal according to Valve Academic Research Consortium 2 criteria (high residual gradient and/or moderate aortic regurgitation) in $61 \%$ post-ViV versus $100 \%$ pre-ViV and $24 \%$ early post-SAVR. ViV procedure was able to restore valve function to the post-SAVR level in only $34 \%$ of patients. Pre-existing prosthesis-patient mismatch (PPM) of the surgical BP as well as BP failure by stenosis were the main factors associated with higher rates of high residual gradient, suboptimal valve haemodynamics and haemodynamic futility following ViV.

How might this impact on clinical practice?

- These findings provide strong support for the prevention of PPM at the time of initial SAVR and for the systematic assessment of PPM as well as the BP mode of failure (stenosis) for the selection of the candidates for ViV and for the consideration of concomitant procedures such as BP stent fracturing at the time of ViV in those patients being at risk for high residual gradients.

haemodynamic futility following ViV. These findings provide strong support for the prevention of PPM at the time of initial SAVR and careful preprocedural patient screening. 


\section{INTRODUCTION}

Transcatheter valve-in-valve (ViV) implantation has emerged as a valuable alternative to treat failed surgical bioprostheses (BPs) in patients with prohibitive or high risk for redo surgical aortic valve replacement (SAVR). ${ }^{1}$ However, high residual gradients (mean aortic gradient $\geq 20 \mathrm{~mm} \mathrm{Hg}$ ) are frequently observed after $\mathrm{ViV}$ procedure. In previous registries, ${ }^{3-7}$ small surgical valve label size $(\leq 21 \mathrm{~mm})$, stenotic pattern of BP degeneration and pre-existing prosthesis-patient mismatch (PPM) of the BP were associated with the persistence of high residual gradient, less improvement in functional capacity and increased risk of mortality following ViV. However, there are relatively few data on the degree of valve haemodynamic improvement following $\mathrm{ViV}$ and on how this procedure eventually restores the valve haemodynamic function to that observed early after initial SAVR. This study aims: (1) to compare the aortic valve haemodynamic status at post-ViV versus pre-ViV and versus early postSAVR and (ii) to determine the factors associated with worse haemodynamic outcomes following ViV, including the rates of high residual gradient and 'haemodynamic futility' (ie, absence of significant valve haemodynamic improvement).

\section{METHODS}

Seventy-nine (79) consecutive patients presenting with a failed surgical BP and deemed unsuitable for redo surgery underwent transcatheter ViV at the Quebec Heart and Lung Institute between 2009 and 2017 and were included in this study.

\section{Doppler echocardiographic measurements}

For each patient included in the study, transthoracic echocardiograms (TTE) performed early (1-3 months) after SAVR (post-SAVR), prior to ViV (pre-ViV) and 1-3 months after ViV (post-ViV) were retrospectively analysed in the echocardiography core laboratory of our institution. The stroke volume was measured in the left ventricular outflow tract (LVOT) with the use of the diameter and velocity measured just underneath the prosthesis stent. The effective orifice area (EOA) was calculated as the LVOT stroke volume divided by the aortic jet velocity time integral and was indexed for body surface area. ${ }^{8}$ The mean aortic pressure gradient (MG) was measured using the modified Bernoulli formula. An integrative, semiquantitative approach was used to grade the severity of aortic regurgitation (AR) as mild, moderate or severe. ${ }^{89}$

At pre-ViV TTE, significant stenosis was defined by a MG $\geq 20 \mathrm{~mm} \mathrm{Hg}$ with an increase $\geq 10 \mathrm{~mm} \mathrm{Hg}$ in MG and decrease $>0.3 \mathrm{~cm}^{2}$ in EOA compared with post-SAVR TTE. ${ }^{810}{ }^{11}$ Patients with stenotic pattern of BP degeneration but less than moderate AR were classified in the stenosis group. Patients with $\geq$ moderate AR without significant stenosis were classified in the AR group. Patient combining both patterns of BP degeneration were classified as having mixed valve dysfunction.
PPM was defined as not clinically significant (ie, mild or no PPM) if the EOA indexed for body surface area $\left(\right.$ EOA $_{\mathrm{i}}$ ) was $>0.85 \mathrm{~cm}^{2} / \mathrm{m}^{2}$, moderate if it was $>0.65 \mathrm{~cm}^{2} /$ $\mathrm{m}^{2}$ but $\leq 0.85 \mathrm{~cm}^{2} / \mathrm{m}^{2}$ and severe if it was $\leq 0.65 \mathrm{~cm}^{2} / \mathrm{m}^{2}$.

Post-SAVR TTE was not available in 20 patients of the study population, and for them, we used the predicted EOA $_{\mathrm{i}}$ to define pre-existing PPM. ${ }^{8}$

\section{Study endpoints}

The primary study endpoints were the presence of suboptimal valve haemodynamic (SVH) function as defined by the Valve Academic Research Consortium (VARC) 2: that is, high residual gradient (MG $\geq 20 \mathrm{~mm} \mathrm{Hg}$ ) and/ or $\geq$ moderate AR. ${ }^{9}$ The secondary endpoints were: (1) haemodynamic 'futility' of the ViV procedure defined as $<10 \mathrm{~mm} \mathrm{Hg}$ decrease in MG and no improvement in AR or worsening compared with pre-ViV; (2) restoration of the valve haemodynamic function to that observed at early post-SAVR TTE, defined as a post-ViV MG within $\pm 10 \mathrm{~mm} \mathrm{Hg}$ of the post-SAVR MG and a post-ViV AR grade less or equivalent to the post-SAVR AR grade.

\section{Statistical analysis}

Continuous data are presented as mean $\pm \mathrm{SD}$ or $\mathrm{SE}$ and were compared between groups using Student's t-test or analysis of variance (ANOVA) and Tukey post hoc test as appropriate. Continuous variable at post-ViV versus pre-ViV or post-SAVR were compared using paired t-tests or two-way repeated measures ANOVA with Holm-Sidak post hoc test. Categorical variables are presented as proportions and were compared using $\chi^{2}$ test or Fisher's exact test as appropriate. Multivariable stepwise forward logistic regression was performed to determine the adjusted correlates for primary and secondary endpoints. Statistical analyses were performed using JMP 13.0 (SAS Institute, USA) and SigmaPlot 11 (Systat Software, USA), and a $p$ value $<0.05$ was considered statistically significant.

\section{RESULTS}

\section{Baseline and ViV procedural characteristics}

Mean age of the patients at the time of ViV was $74.5 \pm 11.0$ years; $66 \%$ were men; $58 \%$ were in New York Heart Association class 3, and the average EuroSCORE in this series was $10.2 \% \pm 2.7 \%$ (table 1 ). The surgical BPs were predominantly stented pericardial valves $(72 \%$ of stented BPs among which $67 \%$ were pericardial) and BP label size ranged from $19 \mathrm{~mm}$ to $29 \mathrm{~mm}$ with a mean internal orifice diameter (IOD) of $20.3 \pm 2.4 \mathrm{~mm}$. The time from SAVR to BP failure requiring ViV was $11 \pm 4$ years (table 2 ). BP mode of failure was stenosis in $40.5 \%$, regurgitation in $31.7 \%$ and mixed in $27.8 \%$. Balloon-expandable (SAPIEN first generation/SAPIEN XT/SAPIEN 3) transcatheter heart valve (THV) type was more frequently $(62 \%)$ used than CoreValve type for ViV in this series (table 3). THV sizes ranged from $20 \mathrm{~mm}$ to $31 \mathrm{~mm}$, the majority of them being $23 \mathrm{~mm}$ valves $(70 \%)$, and transfemoral approach was the predominant access $(60 \%)$. The predominant utilisation of balloon-expandable THVs for $\mathrm{ViV}$ in this 
Table 1 Baseline clinical and Doppler echocardiographic data at the time of initial surgical aortic valve replacement according to the presence or absence of suboptimal aortic valve haemodynamics after ViV

\begin{tabular}{|c|c|c|c|c|}
\hline & & Valve haemodynamics & fter ViV & \\
\hline & $\begin{array}{l}\text { Whole cohort } \\
\mathrm{n}=79\end{array}$ & $\begin{array}{l}\text { Adequate: } \\
\text { MG }<20 \mathrm{~mm} \mathrm{Hg} \text { and } \\
\mathrm{AR} \leq \mathrm{mild} \mathrm{n}=31(39.2 \%)\end{array}$ & $\begin{array}{l}\text { Suboptimal: } \\
M G \geq 20 \mathrm{~mm} \text { Hg and/or } \\
A R \geq \text { moderate } n=48(60.8 \%)\end{array}$ & $P$ values \\
\hline Age, years & $74.5 \pm 11.0$ & $73.6 \pm 12.6$ & $75.0 \pm 9.9$ & 0.587 \\
\hline $\mathrm{BSA}, \mathrm{m}^{2}$ & $1.87 \pm 0.24$ & $1.79 \pm 0.25$ & $1.92 \pm 0.22$ & 0.027 \\
\hline Males, n (\%) & $52(65.8)$ & $18(58.1)$ & $34(70.8)$ & 0.243 \\
\hline EuroSCORE, \% & $10.2 \pm 2.7$ & $10.4 \pm 2.7$ & $10.1 \pm 2.7$ & 0.721 \\
\hline LVEF, $\%$ & $61.5 \pm 9.9$ & $59.5 \pm 13.1$ & $62.7 \pm 7.2$ & 0.237 \\
\hline Stroke volume, mL & $69.3 \pm 14.0$ & $67.4 \pm 12.0$ & $70.6 \pm 15.3$ & 0.392 \\
\hline Surgical BP type, n (\%) & & & & 0.141 \\
\hline Stented porcine & $19(24.1)$ & $8(25.8)$ & $11(22.9)$ & \\
\hline Stented pericardial & $38(48.1)$ & $11(35.5)$ & $27(56.3)$ & \\
\hline Stentless & $22(27.8)$ & $12(38.7)$ & $10(20.8)$ & \\
\hline Surgical BP model, n (\%) & & & & 0.059 \\
\hline Mitroflow & $17(21.5)$ & $6(19.4)$ & $11(22.9)$ & \\
\hline Mosaic & $15(18.9)$ & $7(22.6)$ & $8(16.7)$ & \\
\hline Homograft & $13(16.5)$ & $5(16.1)$ & $8(16.7)$ & \\
\hline Magna & $9(11.4)$ & $1(3.2)$ & $8(16.7)$ & \\
\hline Freestyle & $8(10.1)$ & $6(19.4)$ & $2(4.2)$ & \\
\hline Magna Ease & $6(7.6)$ & $0(0.0)$ & $6(12.5)$ & \\
\hline Perimount & $5(6.3)$ & $3(9.7)$ & $2(4.2)$ & \\
\hline Intact & $2(2.5)$ & $0(0.0)$ & $2(4.2)$ & \\
\hline Hancock & $1(1.3)$ & $0(0.0)$ & $1(2.1)$ & \\
\hline Solo & $1(1.3)$ & $1(3.2)$ & $0(0.0)$ & \\
\hline Trifecta & $1(1.3)$ & $1(3.2)$ & $0(0.0)$ & \\
\hline Epic Supra & $1(1.3)$ & $1(3.2)$ & $0(0.0)$ & \\
\hline Surgical BP size ( $\leq 21 \mathrm{~mm}), \mathrm{n}(\%)$ & $26(32.9)$ & $8(25.8)$ & $18(37.5)$ & 0.280 \\
\hline Internal orifice diameter ${ }^{\star}, \mathrm{mm}$ & $20.3 \pm 2.4$ & $20.8 \pm 2.2$ & $20.0 \pm 2.5$ & 0.131 \\
\hline $\mathrm{MG}, \mathrm{mm} \mathrm{Hg}$ & $14.1 \pm 6.0$ & $11.0 \pm 5.4$ & $16.3 \pm 5.6$ & 0.0007 \\
\hline $\mathrm{EOA}, \mathrm{cm}^{2}$ & $1.59 \pm 0.47$ & $1.70 \pm 0.47$ & $1.52 \pm 0.45$ & 0.087 \\
\hline $\mathrm{EOA}, \mathrm{cm}^{2} / \mathrm{m}^{2}$ & $0.86 \pm 0.26$ & $0.96 \pm 0.27$ & $0.80 \pm 0.23$ & 0.006 \\
\hline Doppler velocity index & $0.38 \pm 0.09$ & $0.40 \pm 0.11$ & $0.37 \pm 0.08$ & 0.428 \\
\hline Pre-existing PPM, n (\%) & & & & 0.032 \\
\hline None & $32(40.5)$ & $18(58.1)$ & $14(29.2)$ & \\
\hline Moderate & $29(36.7)$ & $9(29.0)$ & $20(41.7)$ & \\
\hline Severe & $18(22.8)$ & $4(12.9)$ & $14(29.2)$ & \\
\hline AR & & & & 0.450 \\
\hline None & $25(48.1)$ & $8(40.0)$ & $17(53.1)$ & \\
\hline Trace & $23(44.2)$ & $11(55.0)$ & $12(37.5)$ & \\
\hline Mild & $4(7.7)$ & $1(5.0)$ & $3(9.4)$ & \\
\hline
\end{tabular}

${ }^{*}$ According to the Bapat's ViV application.

AR, aortic regurgitation; BP, bioprosthesis; BSA, body surface area; EOA, effective orifice area; EOA , indexed EOA; LVEF, left ventricular ejection fraction; MG, mean transvalvular pressure gradient; PPM, prosthesis-patient mismatch; ViV, valve-in-valve implantation.

study is mainly related to the fact that our centre started the transcatheter aortic valve replacement programme with SAPIEN THVs, and for several years, this was the only type of THV used for these procedures. The ratio of balloon expandable versus self-expanding THVs for ViV has however decreased markedly and shifted during the 
Table 2 Doppler echocardiographic data prior to ViV procedure according to the presence or absence of suboptimal aortic valve haemodynamic performance after ViV

\begin{tabular}{|c|c|c|c|c|}
\hline & \multirow[b]{2}{*}{$\begin{array}{l}\text { Whole cohort } \\
\mathrm{n}=79\end{array}$} & \multicolumn{2}{|c|}{ Valve haemodynamics after ViV } & \multirow[b]{2}{*}{$P$ values } \\
\hline & & $\begin{array}{l}\text { Adequate: } \\
\mathrm{MG}<20 \mathrm{~mm} \mathrm{Hg} \text { and } \\
\mathrm{AR} \leq \mathrm{mild} \mathrm{n}=31(39.2 \%)\end{array}$ & $\begin{array}{l}\text { Suboptimal: } \\
M G \geq 20 \mathrm{~mm} \mathrm{Hg} \text { and/or } \\
A R \geq \text { moderate } \mathrm{n}=48(60.8 \%)\end{array}$ & \\
\hline Time to failure, years & $11.1 \pm 4.2$ & $11.3 \pm 4.0$ & $10.9 \pm 4.3$ & 0.724 \\
\hline BP mode of failure, $n(\%)$ & & & & 0.035 \\
\hline AS & $32(40.5)$ & $9(29.0)$ & $23(47.9)$ & \\
\hline AR & $25(31.7)$ & $15(48.4)$ & $10(20.8)$ & \\
\hline Mixed & $22(27.8)$ & $7(22.6)$ & $15(31.3)$ & \\
\hline LVEF, \% & $58.9 \pm 10.9$ & $55.8 \pm 13.1$ & $60.8 \pm 8.9$ & 0.047 \\
\hline Stroke volume, $\mathrm{mL}$ & $82.2 \pm 20.7$ & $79.6 \pm 18.7$ & $83.8 \pm 21.9$ & 0.398 \\
\hline $\mathrm{MG}, \mathrm{mm} \mathrm{Hg}$ & $36.6 \pm 20.2$ & $28.0 \pm 17.4$ & $42.2 \pm 20.1$ & 0.002 \\
\hline $\mathrm{EOA}, \mathrm{cm}^{2}$ & $1.04 \pm 0.52$ & $1.21 \pm 0.60$ & $0.95 \pm 0.44$ & 0.031 \\
\hline $\mathrm{EOA}, \mathrm{cm}^{2} / \mathrm{m}^{2}$ & $0.57 \pm 0.29$ & $0.68 \pm 0.34$ & $0.50 \pm 0.23$ & 0.009 \\
\hline Doppler velocity index & $0.27 \pm 0.13$ & $0.33 \pm 0.18$ & $0.24 \pm 0.09$ & 0.008 \\
\hline AR, n (\%) & & & & 0.368 \\
\hline None & $7(9.0)$ & $1(3.3)$ & $6(12.5)$ & \\
\hline Trace & $15(19.2)$ & $5(16.7)$ & $10(20.8)$ & \\
\hline Mild & $11(14.1)$ & $4(13.3)$ & $7(14.6)$ & \\
\hline Moderate & $25(32.1)$ & $9(30.0)$ & $16(33.3)$ & \\
\hline Severe & $20(25.6)$ & $11(36.7)$ & $9(18.8)$ & \\
\hline$A R \geq$ moderate, $n(\%)$ & $45(57.7)$ & $20(66.7)$ & $25(52.1)$ & 0.205 \\
\hline
\end{tabular}

AR, aortic regurgitation; AS, aortic stenosis; BP, bioprosthesis; BSA, body surface area; EOA, effective orifice area; EOA, indexed EOA; LVEF, left ventricular ejection fraction; MG, mean transvalvular pressure gradient; Mixed, mixed dysfunction; PPM, prosthesis-patient mismatch; ViV, valve-in-valve implantation.

past 5 years, and nowadays $>65 \%$ of the THVs used for $\mathrm{ViV}$ are CoreValve devices (online supplementary figure $1)$.

Forty-seven $(47 ; 59.5 \%)$ patients had pre-existing PPM of the surgical BP: 29 of them had moderate $(36.7 \%)$ and 18 patients had severe (22.8\%) PPM. These patients received stented BPs more frequently than patients free of pre-existing PPM $(p<0.0001)$ and the percentage of BP with $\leq 21 \mathrm{~mm}$ label size was numerically (but not statistically) higher in patients with pre-existing PPM $(50 \%$ in patients with severe PPM, $31 \%$ in patients with moderate PPM and $25 \%$ in patients free of PPM; $\mathrm{p}=0.19$ ) (online supplementary table 1). BPs with pre-existing severe or moderate PPM failed more frequently by stenosis with a shorter time from SAVR to BP failure and were more frequently treated with small THVs (THV $\leq 23 \mathrm{~mm}$ ) compared with patients free of pre-existing PPM $(94.4 \%$, $82.8 \%$ and $43.8 \%$, respectively, $\mathrm{p}=0.0001$ ) (online supplementary tables 2 and 3 ).

\section{ViV haemodynamic outcomes}

Forty-eight (61\%) patients met the VARC2-based primary endpoint of SVH after ViV procedure. Among them, the vast majority (45 patients) had high residual gradient and only three had moderate AR after ViV.
Compared with patients with adequate haemodynamic performance after ViV, patients with SVH had larger body surface area and MG, smaller $\mathrm{EOA}_{i}$ and more pre-existing PPM at the time of initial SAVR (table 1), as well as more BPs with stenosis pattern of degeneration (table 2). Regarding echocardiographic Doppler data pre-ViV (table 2) and post-ViV (table 3), patients with SVH had higher MG and smaller EOA, EOA, and Doppler velocity index. Finally, these patients had a larger increase in MG from post-SAVR to post-ViV (table 3).

High residual gradient after $\mathrm{ViV}$ was more frequently met in patients with severe $(78 \%)$ or moderate $(69 \%)$ pre-existing PPM compared with those without PPM $(34 \%) \quad(\mathrm{p}<0.01) \quad$ (online supplementary figure 2 , online supplementary table 3 ). High residual gradient after ViV was also more frequent in patients with stenosis $(72 \%)$ and combined degeneration pattern of the BP (68\%) compared with patients with regurgitant pattern $(28 \%)$ $(p<0.002)$ (online supplementary figure 2 ).

\section{Comparison of valve haemodynamic status at post-SAVR, pre- ViV and post-ViV}

As expected, EOA decreased and $\mathrm{MG}$ and rate of $\geq$ moderate AR increased from post-SAVR to pre-ViV TTEs (tables 1 and 2, figures 1 and 2). After ViV, MG and 
Table 3 Procedural data and Doppler echocardiographic data post-ViV according to the presence or absence of suboptimal aortic valve haemodynamic performance after ViV

\begin{tabular}{|c|c|c|}
\hline Whole & Valve haemodynamics & after ViV \\
\hline & $\begin{array}{l}\text { Adequate: } \\
\mathrm{MG}<20 \mathrm{~mm} \mathrm{Hg} \text { and }\end{array}$ & $\begin{array}{l}\text { Suboptimal: } \\
M G \geq 20 \mathrm{~mm} \mathrm{Hg} \text { and/or }\end{array}$ \\
\hline$n=79$ & AR $\leq$ mild $n=31$ (39.2\%) & $A R \geq$ moderate $n=48(60.8 \%)$ \\
\hline
\end{tabular}

\begin{tabular}{|c|c|c|c|c|}
\hline \multicolumn{5}{|l|}{ Procedural data } \\
\hline Balloon-expandable THV, n (\%) & $49(62.0)$ & $19(61.3)$ & $30(62.5)$ & 0.914 \\
\hline THV size ( $\leq 23), n(\%)$ & $55(69.6)$ & $19(61.3)$ & $36(75.0)$ & 0.196 \\
\hline THV model, $\mathrm{n}(\%)$ & & & & 0.484 \\
\hline SAPIEN/XT/3 & $49(62.0)$ & $19(61.3)$ & $30(62.5)$ & \\
\hline CoreValve/Evolut R & $28(35.4)$ & $12(38.7)$ & $16(33.3)$ & \\
\hline Portico & $2(2.5)$ & $0(0.0)$ & $2(4.2)$ & \\
\hline Access, $n(\%)$ & & & & 0.224 \\
\hline Transfemoral & $47(59.5)$ & $16(51.6)$ & $31(64.6)$ & \\
\hline Transapical & $23(29.1)$ & $12(38.7)$ & $11(22.9)$ & \\
\hline Transcarotid & $6(7.6)$ & $1(3.2)$ & $5(10.4)$ & \\
\hline Transaortic & $3(3.8)$ & $2(6.5)$ & $1(2.1)$ & \\
\hline Procedural success, $\mathrm{n}(\%)$ & $62(78.5)$ & $24(77.4)$ & $38(79.2)$ & 0.854 \\
\hline Coronary occlusion, n (\%) & $1(1.3)$ & $0(0)$ & $1(2.1)$ & 1.0 \\
\hline More than one THV, $\mathrm{n}(\%)$ & $8(10.1)$ & $3(9.7)$ & $5(10.4)$ & 1.0 \\
\hline Need of pacemaker, $\mathrm{n}(\%)$ & $3(3.8)$ & $0(0.0)$ & $3(6.3)$ & 0.276 \\
\hline New onset of atrial fibrillation, $n(\%)$ & $5(6.8)$ & $2(6.7)$ & $3(6.8)$ & 1.0 \\
\hline Major vascular complication, n (\%) & $2(2.5)$ & $1(3.2)$ & $1(2.1)$ & 1.0 \\
\hline Major bleeding, $\mathrm{n}(\%)$ & $3(3.8)$ & $1(3.2)$ & $2(4.2)$ & 1.0 \\
\hline THV malposition or embolisation, $n$ (\%) & $2(2.5)$ & $0(0.0)$ & $2(4.2)$ & 0.517 \\
\hline Hospital stay, days & $6.9 \pm 4.9$ & $7.7 \pm 5.5$ & $6.3 \pm 4.4$ & 0.214 \\
\hline \multicolumn{5}{|c|}{$\begin{array}{l}\text { Doppler echocardiographic data post- } \\
\text { ViV }\end{array}$} \\
\hline MG, mm Hg & $22.2 \pm 9.3$ & $14.1 \pm 3.9$ & $27.3 \pm 8.0$ & $<0.0001$ \\
\hline $\mathrm{EOA}, \mathrm{cm}^{2}$ & $1.15 \pm 0.38$ & $1.29 \pm 0.29$ & $1.06 \pm 0.40$ & 0.009 \\
\hline $\mathrm{EOA}, \mathrm{cm}^{2} / \mathrm{m}^{2}$ & $0.62 \pm 0.21$ & $0.73 \pm 0.18$ & $0.56 \pm 0.20$ & 0.0003 \\
\hline Doppler velocity index & $0.30 \pm 0.08$ & $0.34 \pm 0.08$ & $0.27 \pm 0.07$ & $<0.0001$ \\
\hline PPM, n (\%) & & & & $<0.0001$ \\
\hline None & $11(13.9)$ & $8(25.8)$ & $3(6.3)$ & \\
\hline Moderate & $14(17.7)$ & $12(38.7)$ & $2(4.2)$ & \\
\hline Severe & $54(68.4)$ & $11(35.5)$ & $43(89.6)$ & \\
\hline LVEF, \% & $57.5 \pm 11.7$ & $55.8 \pm 10.7$ & $58.7 \pm 11.7$ & 0.584 \\
\hline Stroke volume, $\mathrm{mL}$ & $70.2 \pm 18.5$ & $72.0 \pm 24.0$ & $67.9 \pm 14.2$ & 0.684 \\
\hline$A R, n(\%)$ & & & & 0.035 \\
\hline None & $26(33.3)$ & $8(26.7)$ & $18(37.5)$ & \\
\hline Trace & $39(50.0)$ & $16(53.3)$ & $23(47.9)$ & \\
\hline Mild & $10(12.8)$ & $6(20.0)$ & $4(8.3)$ & \\
\hline Moderate & $3(3.9)$ & $0(0.0)$ & $3(6.3)$ & \\
\hline Severe & $0(0.0)$ & $0(0.0)$ & $0(0.0)$ & \\
\hline \multicolumn{5}{|l|}{ Suboptimal valve function } \\
\hline $\mathrm{MG} \geq 20 \mathrm{~mm} \mathrm{Hg}, \mathrm{n}(\%)$ & $45(57.0)$ & $0(0.0)$ & $45(93.8)$ & - \\
\hline$A R \geq$ moderate, $n(\%)$ & $3(3.9)$ & $0(0.0)$ & $3(6.3)$ & - \\
\hline
\end{tabular}


Table 3 Continued

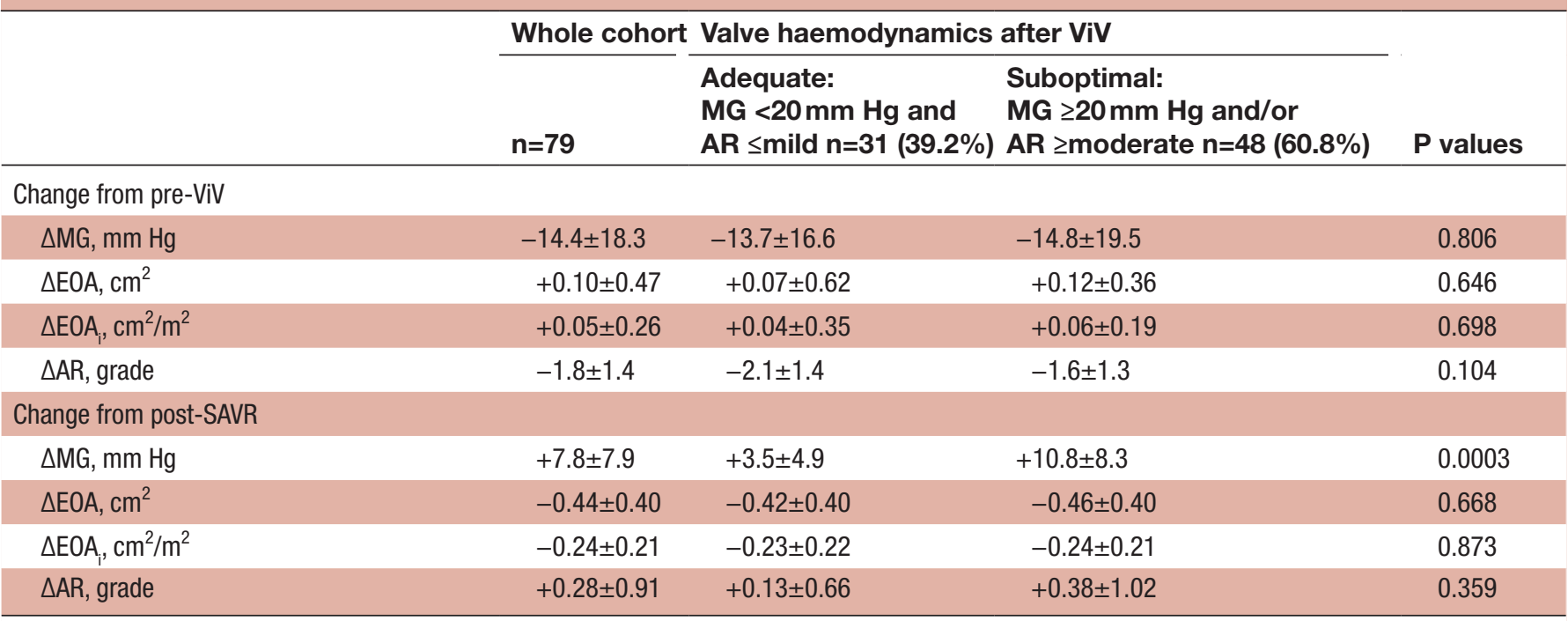

*Procedural success was defined as the absence of any major adverse cardiovascular and cerebrovascular event (stroke, myocardial infarction, in-hospital death) and device success (no more than one transcatheter prosthesis, no procedural death and no vascular complication).

$A R$, aortic regurgitation; EOA, effective orifice area; $E O A$, indexed EOA; LVEF, left ventricular ejection fraction; MG, mean transvalvular pressure gradient; PPM, prosthesis-patient mismatch; SAVR, surgical aortic valve replacement; THV, transcatheter heart valve; ViV, valve-invalve implantation.

rate of $\geq$ moderate AR decreased significantly compared with pre-ViV, but they nonetheless remained higher compared with early post-SAVR (tables 2 and 3, figures 1 and 2, online supplementary figure 3). SVH function was present in 24\% (high residual gradient: $24 \%$, AR: $0 \%$ ) of patients post-SAVR, in $100 \%$ of the patients pre-ViV (high residual gradient: $75 \%$, AR: $58 \%$ ) and in $61 \%$ (high residual gradient: 57\%, AR: 4\%) of patients post-ViV $(\mathrm{p}<0.0001)$ (figure 2).

The criteria of haemodynamic futility of ViV were observed in $7.6 \% \quad(n=6)$ of the whole cohort (figure 3$)$. $\mathrm{ViV}$ restored valve haemodynamic function to that observed at early post-SAVR in only $34 \%$ of patients in this series (figure 3).

\section{Factors associated with ViV haemodynamic outcomes}

In univariable analysis, the factors associated with SVH after ViV procedure were: BP mode of failure (AS and mixed vs AR) and moderate or severe pre-existing PPM after SAVR (table 4). The factors associated with isolated high residual gradient after ViV were: BP type (pericardial stented vs stentless), smaller BP IOD, mode of BP failure (AS and mixed vs AR), moderate or severe pre-existing PPM after SAVR and THV size $\leq 23 \mathrm{~mm}$ (table 4 ). In multivariable analysis, pre-existing PPM and BP mode of failure (AS and mixed) remained significantly associated with SVH and with higher risk of high residual gradient after ViV (table 4).

Criteria of haemodynamic futility of ViV were more frequently met in patients harbouring concomitant pre-existing PPM (moderate or severe) and stenosis pattern of BP degeneration (18.5\%) compared with patients with no PPM and/or combined/regurgitant pattern of BP degeneration (2.0\%) (figure 3 ).

The presence of a stented porcine BP was the only factor associated with restoration of valve haemodynamic function to that observed post-SAVR (OR: $4.58,95 \%$ CI 1.15 to $18.28 ; \mathrm{p}=0.03)$.

\section{DISCUSSION}

The main findings of this study were: (i) ViV was associated with an improvement in valve haemodynamics compared with pre-ViV in $92 \%$ of patients. (2) However, SVH-as defined by VARC2 criteria-was observed in $61 \%$ of patients post-ViV versus $24 \%$ early post-SAVR. (3) $\mathrm{ViV}$ was able to restore valve function to that observed post-SAVR in only $34 \%$ of patients. (4) Pre-existing PPM of the surgical BP and BP mode of failure by stenosis were the main factors associated with higher rates of high residual gradient and SVH following ViV and of haemodynamic futility of this procedure.

\section{Haemodynamic outcomes of ViV versus initial SAVR}

About one quarter of patients had SVH (exclusively high residual gradient) early after initial SAVR. This is most likely related to the presence of severe PPM. However, following $\mathrm{ViV}$, this rate of $\mathrm{SVH}$ increased by 2.5 folds compared with post-SAVR, and only one-third of the patients had a restoration of their valve haemodynamic function to the post-SAVR level following ViV (figures 2 and 3). These findings may be explained by the fact that the ViV procedure (ie, implanting a second valve within a pre-existing one) generally reduces the internal orifice area available for blood flow, unless the BP is expanded 
A

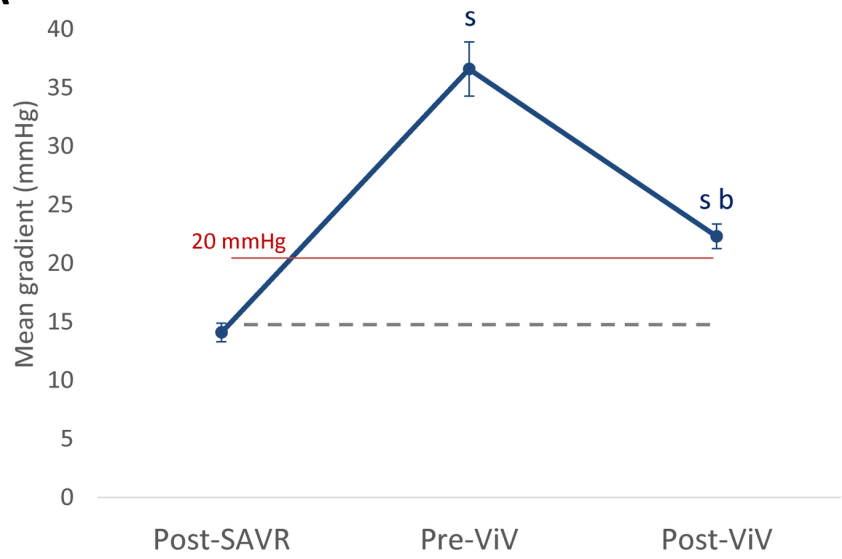

B

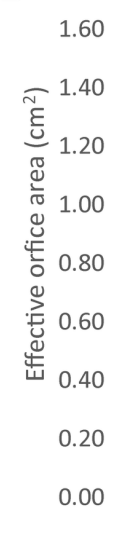

Figure 1 Haemodynamic performance of the aortic bioprosthesis early after SAVR, before and after ViV. Panel A shows the mean transvalvular pressure gradient, panel $\mathrm{B}$ shows the effective orifice area and panel $\mathrm{C}$ shows the distribution of aortic regurgitation grades. 'Statistical difference versus post-SAVR; 'Statistical difference versus pre-ViV. AR, aortic regurgitation; SAVR, surgical aortic valve replacement; ViV, valve-in-valve.

or fractured during the procedure. An analogy to this concept would be the Russian dolls, where the second doll is necessarily smaller than the first one. Hence, although the valve haemodynamic status of the failed BP is significantly improved (ie, gradient and/or AR are reduced compared with pre-ViV) in the vast majority of patients, the $\mathrm{ViV}$ procedure is generally not able to restore the baseline valve function post-SAVR.

The only factor associated with restoration of valve function to that observed early post-SAVR was the presence of stented porcine BP. In stented porcine BPs, the leaflets are mounted within the stent, whereas in most stented pericardial BPs (eg, Mitroflow) included in this study, the leaflets were mounted outside the stent. Hence, in pericardial BPs, ViV generally leads to a worsening of valve haemodynamics, whereas in stented porcine BPs, the radial forces exerted by the THV during ViV may compress the BP leaflet tissue and sutures and therefore expand the internal geometric orifice area of the BP. These factors may have resulted in less decrease, or even some increase, in the internal geometric orifice area and EOA of stented porcine BPs compared with stented pericardial BPs. These findings are consistent with recent in vitro studies that reported no increase in gradients after ViV implantation of the SAPIEN ${ }^{12}$ and the CoreValve ${ }^{13}$ within normally functioning porcine BPs.

\section{Factors associated with ViV haemodynamic outcomes}

Several studies reported that severe pre-existing PPM of the BP is associated with worse functional capacity, increased risk of mortality and increased rates of high residual gradient after ViV. ${ }^{6}$ However, the vast majority of previous studies have focused on the post-ViV haemodynamic status and did not compare with the pre-ViV and post-SAVR status. Furthermore, significant haemodynamic and clinical benefit may occur following ViV despite the presence of high residual gradients after the procedure. For example, a reduction in pre-ViV mean gradient of $60 \mathrm{~mm} \mathrm{Hg}$ to post-ViV of $25 \mathrm{~mm} \mathrm{Hg}$ will likely significantly improve the functional status of the patient. 


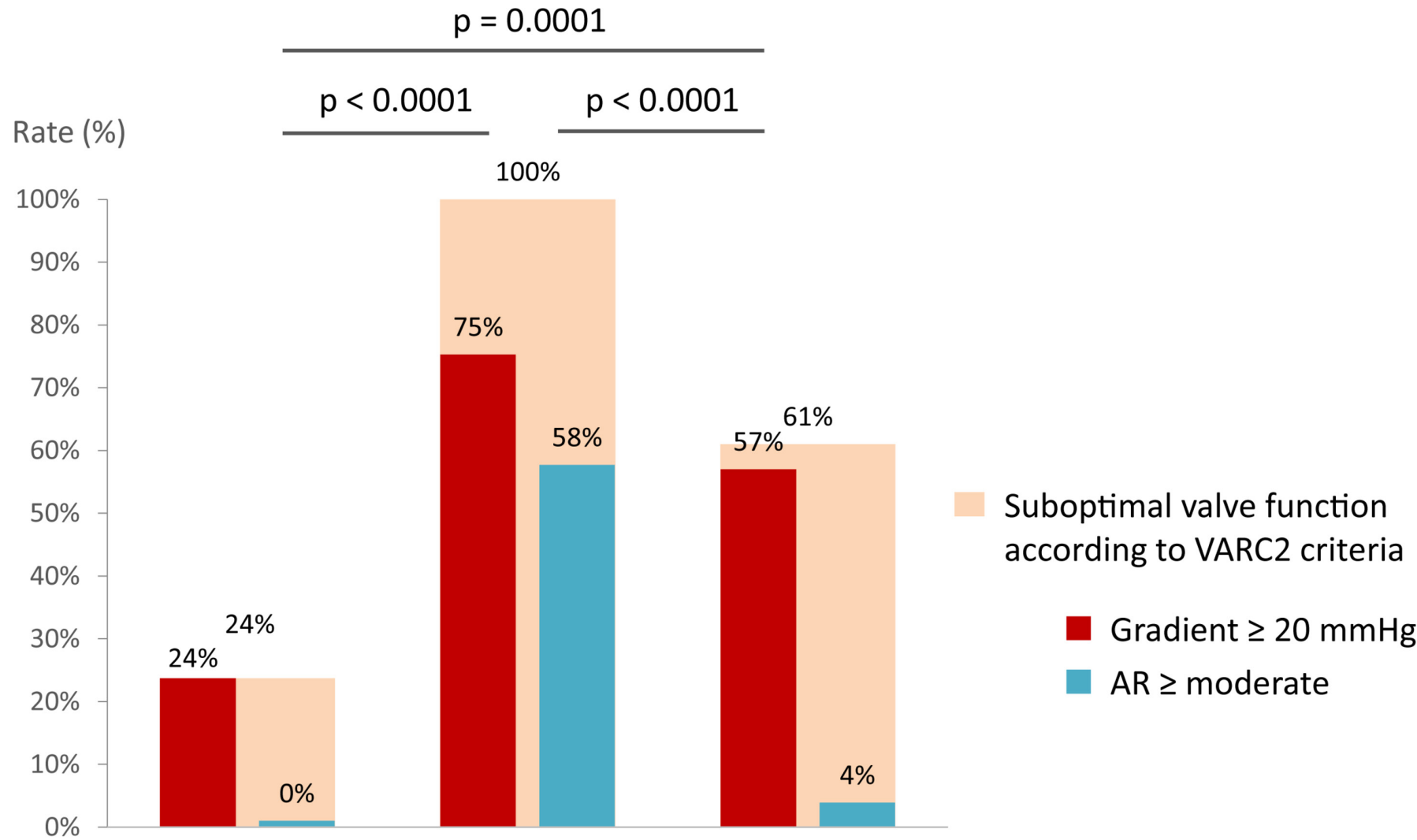

Post-SAVR

Pre-ViV

Post-ViV

Figure 2 Suboptimal aortic valve haemodynamics according to the VARC2 criteria (MG $\geq 20 \mathrm{~mm} \mathrm{Hg}$ or AR $\geq \mathrm{moderate}$ ) early post-SAVR, pre-ViV and post-ViV. AR, aortic regurgitation; SAVR, surgical aortic valve replacement; VARC 2, Valve Academic Research Consortium 2; ViV, valve-in-valve.

The concept of treatment futility has been applied in the context of transcatheter valve therapy to functional and clinical outcomes, but the same principles may also be applied to haemodynamic outcomes. ${ }^{14-16}$ We thus defined haemodynamic futility as the absence of significant improvement in transprosthetic gradient $(<10 \mathrm{~mm} \mathrm{Hg})$ and AR (<1 grade). In the present study, $\mathrm{ViV}$ was haemodynamically futile in $7.6 \%$ of the patients.

Pre-existing PPM of the surgical BP was associated with increased risk of high residual gradients after $\mathrm{ViV}$ and haemodynamic futility of ViV. Indeed, in a patient with severe pre-existing PPM, the EOA is already small at the time of SAVR and a ViV generally further reduces the $\mathrm{EOA}_{\mathrm{i}}$ and worsens the haemodynamic status (ie, fitting a second doll in an already small doll). Patients with no-pre-existing PPM nonetheless harboured less improvement in EOA and gradients compared with those with pre-existing PPM (online supplementary table 3, online supplementary figure 3). Patients with no pre-existing PPM also often are those in whom regurgitation
A

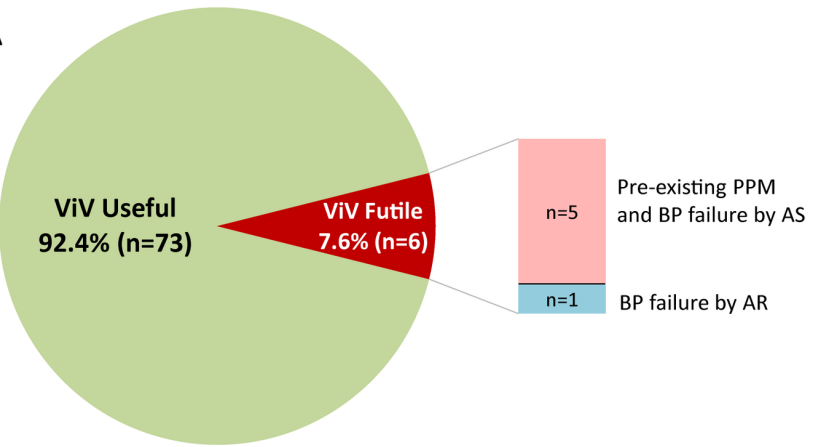

B

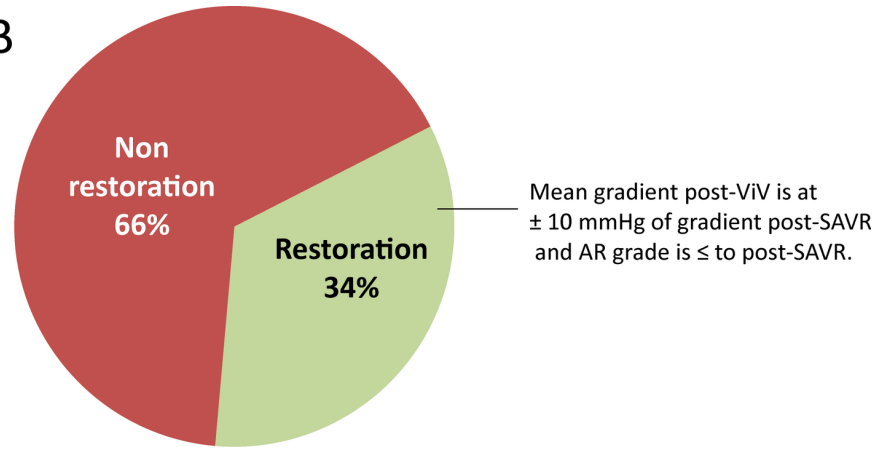

Figure 3 ViV haemodynamic futility and restoration of SAVR valve function. Panel A shows haemodynamic futility of the ViV procedure, defined as no improvement in AR and $<10 \mathrm{~mm} \mathrm{Hg}$ decrease in mean aortic gradient. Panel $B$ shows the rate of restoration of the valve haemodynamic function to that observed early after SAVR. AR, aortic regurgitation; AS, aortic stenosis; BP, bioprosthesis; n, number of patients; PPM, prosthesis-patient mismatch; SAVR, surgical aortic valve replacement; ViV, valve-in-valve. 
Table 4 Univariable and multivariable analyses of the factors associated with post-ViV high residual gradient and/ or $\geq$ moderate aortic regurgitation

\begin{tabular}{|c|c|c|c|c|c|c|c|c|}
\hline & \multicolumn{4}{|c|}{$\begin{array}{l}\text { High gradient } \\
\text { (MG } \geq 20 \mathrm{~mm} \mathrm{Hg})\end{array}$} & \multicolumn{4}{|c|}{$\begin{array}{l}\text { High gradient and/or } \\
\text { AR } \geq \text { moderate }\end{array}$} \\
\hline & \multicolumn{2}{|c|}{ Univariable analysis } & \multicolumn{2}{|c|}{ Multivariable analysis } & \multicolumn{2}{|c|}{ Univariable analysis } & \multicolumn{2}{|c|}{ Multivariable analysis } \\
\hline & $\begin{array}{l}\text { OR } \\
(95 \% \mathrm{Cl})\end{array}$ & $\begin{array}{l}\mathbf{P} \\
\text { values }\end{array}$ & $\begin{array}{l}\text { OR } \\
(95 \% \mathrm{Cl})\end{array}$ & $\begin{array}{l}\mathbf{P} \\
\text { values }\end{array}$ & $\begin{array}{l}\text { OR } \\
(95 \% \mathrm{Cl})\end{array}$ & $\begin{array}{l}\mathbf{P} \\
\text { values }\end{array}$ & $\begin{array}{l}\text { OR } \\
(95 \% \mathrm{Cl})\end{array}$ & $\begin{array}{l}\mathbf{P} \\
\text { values }\end{array}$ \\
\hline Male & $\begin{array}{l}1.37 \\
(0.54 \text { to } 3.50)\end{array}$ & 0.509 & - & - & $\begin{array}{l}1.75 \\
(0.68 \text { to } 4.52)\end{array}$ & 0.245 & - & - \\
\hline $\begin{array}{l}\text { BP type (stented vs } \\
\text { stentless) }\end{array}$ & $\begin{array}{l}4.29 \\
(1.50 \text { to } 12.28)\end{array}$ & 0.007 & - & - & $\begin{array}{l}2.40 \\
(0.88 \text { to } 6.55)\end{array}$ & 0.087 & - & - \\
\hline \multicolumn{9}{|l|}{ BP type } \\
\hline $\begin{array}{l}\text { Stented pericardial vs } \\
\text { stentless }\end{array}$ & $\begin{array}{l}5.26 \\
\text { (1.69 to } 16.42)\end{array}$ & 0.004 & - & - & $\begin{array}{l}2.95 \\
(0.99 \text { to } 8.79)\end{array}$ & 0.053 & - & - \\
\hline $\begin{array}{l}\text { Stented porcine vs } \\
\text { stentless }\end{array}$ & $\begin{array}{l}2.95 \\
(0.82 \text { to } 10.58)\end{array}$ & 0.098 & - & - & $\begin{array}{l}1.65 \\
(0.48 \text { to } 5.69)\end{array}$ & 0.428 & - & - \\
\hline $\mathrm{BP}$ size $(\leq 21 \mathrm{~mm})$ & $\begin{array}{l}2.17 \\
(0.80 \text { to } 5.84)\end{array}$ & 0.127 & - & - & $\begin{array}{l}1.73 \\
(0.64 \text { to } 4.66)\end{array}$ & 0.283 & - & - \\
\hline BP IOD, mm & $\begin{array}{l}0.72 \\
(0.58 \text { to } 0.91)\end{array}$ & 0.005 & - & - & $\begin{array}{l}0.86 \\
(0.71 \text { to } 1.05)\end{array}$ & 0.135 & - & - \\
\hline $\begin{array}{l}\text { BP mode of failure (AS or } \\
\text { mixed vs AR) }\end{array}$ & $\begin{array}{l}6.11 \\
(2.14 \text { to } 17.46)\end{array}$ & 0.001 & $\begin{array}{l}5.37 \\
(1.77 \text { to } 16.30)\end{array}$ & 0.003 & $\begin{array}{l}3.56 \\
(1.32 \text { to } 9.59)\end{array}$ & 0.012 & $\begin{array}{l}3.02 \\
(1.08 \text { to } 8.42)\end{array}$ & 0.035 \\
\hline $\begin{array}{l}\text { Pre-existing PPM } \\
\text { ( } \geq \text { moderate) }\end{array}$ & $\begin{array}{l}4.99 \\
(1.89 \text { to } 13.17)\end{array}$ & 0.001 & $\begin{array}{l}4.38 \\
(1.55 \text { to } 12.37)\end{array}$ & 0.005 & $\begin{array}{l}3.36 \\
(1.31 \text { to } 8.67)\end{array}$ & 0.012 & $\begin{array}{l}2.87 \\
(1.08 \text { to } 7.65)\end{array}$ & 0.035 \\
\hline $\begin{array}{l}\text { THV type } \\
\text { (balloon expandable vs } \\
\text { self-expanding) }\end{array}$ & $\begin{array}{l}1.27 \\
(0.51 \text { to } 3.17)\end{array}$ & 0.611 & - & - & $\begin{array}{l}1.05 \\
(0.42 \text { to } 2.67)\end{array}$ & 0.914 & - & - \\
\hline $\begin{array}{l}\text { THV design (intra-annular } \\
\text { vs supra-annular) }\end{array}$ & $\begin{array}{l}1.55 \\
(0.61 \text { to } 3.93)\end{array}$ & 0.356 & - & - & $\begin{array}{l}1.26 \\
(0.49 \text { to } 3.23)\end{array}$ & 0.626 & - & - \\
\hline THV size $(\leq 23 \mathrm{~mm})$ & $\begin{array}{l}3.16 \\
\text { (1.17 to } 8.55)\end{array}$ & 0.024 & - & - & $\begin{array}{l}1.90 \\
\text { (0.72 to } 5.02)\end{array}$ & 0.199 & - & - \\
\hline
\end{tabular}

AR, aortic regurgitation; AS, aortic stenosis; BP, bioprosthesis; IOD, internal orifice diameter; MG, mean transaortic gradient; mixed, mixed dysfunction; PPM, prosthesis-patient mismatch; THV, transcatheter heart valve; ViV, valve-in-valve.

or mixed dysfunction is the predominant mechanism of BP failure. In such patients, the valve haemodynamic improvement following ViV is essentially related to the reduction in transprosthetic regurgitation, and there is thus no or minimal decrease in gradients per se.

Overall, these findings further emphasise the paramount importance of: (1) avoiding PPM, especially severe PPM, at the time of initial SAVR and (2) performing systematic screening for the presence of pre-existing PPM and/or acquired BP stenosis at the time of pre-ViV assessment. The new BP generations implanted in a supra-annular position allow to surgeon to achieve the prevention of severe PPM in most patients. Another option would be to perform a transcatheter aortic valve replacement in place of SAVR. Indeed, PPM is less frequent with transcatheter aortic valve replacement than with SAVR, and ViV within a THV is associated with better haemodynamics results than within a surgical BP. ${ }^{17}$

BP mode of failure by stenosis is also associated with higher risk of high residual gradients and haemodynamic futility following ViV. This may be explained by the fact that the thickened and calcified leaflets of the failed surgical BP may limit the expansion of the THV within the BP during ViV.

Hence, the haemodynamic utility versus futility ratio of the ViV procedure should be carefully evaluated in patients with severe pre-existing PPM and/or BP stenosis. In patients with severe PPM, one may consider fracturing the BP stent with a non-compliant balloon. ${ }^{18}{ }^{19}$ Further studies are however needed to assess the risk-benefit ratio and long-term outcomes of this procedure. The findings of this study also provide support to the development of new generations of surgical BPs with expansible stents to allow the implantation of a larger THV at the time of ViV.

Several studies reported that THV with supra-annular design are associated with lower rates of high residual gradient after VIV compared with THV with intra-annular design, especially in patients with small BPs and/or BPs with severe PPM. ${ }^{420}$ In the present study, the THV design was not found to be associated with worse haemodynamic outcomes after ViV. Intra-annular THVs were used in the vast majority of the patients included in this 
series, and the supra-annular THVs were used specifically in small BPs.

\section{CONCLUSIONS}

$\mathrm{ViV}$ is associated with a significant improvement in valve haemodynamics compared with pre-ViV in $>90 \%$ of patients. However, SVH as defined by VARC2 criteria occurred in $61 \%$ ( $57 \%$ high residual gradient) of patients post-ViV versus $24 \%$ early post-SAVR. Furthermore, ViV was able to restore valve function to the post-SAVR level in only $34 \%$ of patients. Pre-existing PPM and BP failure by stenosis were the main factors associated with higher rates of high residual gradient, SVH and haemodynamic futility following ViV. These findings provide strong support for the prevention of PPM at the time of initial SAVR and for the consideration of BP stent fracturing at the time of $\mathrm{ViV}$ if severe pre-existing PPM is present.

Acknowledgements We would like to thank Céline Boutin, Martine Parent and Danielle Tardif for their help in echocardiographic reading and data gathering.

Contributors The study was planned and conducted by A-SZ and PP. AD, ES, JR-C, MC, RDL, J-MP, DD, SM, ER, CC and TR-G were involved in clinical and/or echocardiographic data acquisition. A-SZ, AD, ES, M-AC and PP performed and/or supervised data management and statistical analyses. A-SZ, AD, ES, M-AC, GO, EG, $\mathrm{RR}$ and $\mathrm{PP}$ contributed to the interpretation of the data. The manuscript was drafted by A-SZ. ES, M-AC, GO, EG and PP made critical revisions. All authors read and approved the final manuscript.

Funding This study was funded by a Foundation Scheme Grant (\#FDN-143225) from Canadian Institutes of Health Research (Ottawa, Ontario, Canada). PP holds the Canada Research Chair in Valvular Heart Disease. JR-C holds the Research Chair on the Development of Interventional Therapies for Structural Heart Diseases - Family Jacques Larivière Foundation.

Competing interests PP and JR-C report research grant from Edwards Lifesciences and Medtronic.

Patient consent Not required.

Provenance and peer review Not commissioned; externally peer reviewed.

Open access This is an open access article distributed in accordance with the Creative Commons Attribution Non Commercial (CC BY-NC 4.0) license, which permits others to distribute, remix, adapt, build upon this work non-commercially, and license their derivative works on different terms, provided the original work is properly cited, appropriate credit is given, any changes made indicated, and the use is non-commercial. See:http://creativecommons.org/licenses/by-nc/4.0/.

\section{REFERENCES}

1. Nishimura RA, Otto CM, Bonow RO, et al. 2017 AHA/ACC focused update of the 2014 AHA/ACC guideline for the management of patients with valvular heart disease: a report of the American College of Cardiology/American Heart Association Task Force on Clinical Practice Guidelines. J Am Coll Cardiol 2017;70:252-89.

2. Baumgartner H, Falk V, Bax JJ, et al. 2017 ESC/EACTS guidelines for the management of valvular heart disease: the task force for the management of valvular heart disease of the European Society of
Cardiology (ESC) and the European Association for Cardio-Thoracic Surgery (EACTS). Eur Heart J 2017;38:2739-91.

3. Dvir D, Webb JG, Bleiziffer S, et al. Transcatheter aortic valve implantation in failed bioprosthetic surgical valves. JAMA 2014;312:162-70.

4. Simonato M, Webb J, Kornowski R, et al. Transcatheter replacement of failed bioprosthetic valves: large multicenter assessment of the effect of implantation depth on hemodynamics after aortic valve-invalve. Circ Cardiovasc Interv 2016;9.

5. Webb JG, Mack MJ, White JM, et al. Transcatheter aortic valve implantation within degenerated aortic surgical bioprostheses: partner 2 valve-in-valve registry. J Am Coll Cardiol 2017;69:2253-62.

6. Deeb GM, Chetcuti SJ, Reardon MJ, et al. 1-year results in patients undergoing transcatheter aortic valve replacement with failed surgical bioprostheses. JACC Cardiovasc Interv 2017;10:1034-44.

7. Pibarot $\mathrm{P}$, Simonato $\mathrm{M}$, Barbanti M, et al. Impact of pre-existing prosthesis-patient mismatch on survival following aortic valve-invalve procedures. JACC Cardiovasc Interv 2018;11:133-41.

8. Lancellotti P, Pibarot P, Chambers J, et al. Recommendations for the imaging assessment of prosthetic heart valves: a report from the European Association of Cardiovascular Imaging endorsed by the Chinese Society of Echocardiography, the Inter-American Society of Echocardiography, and the Brazilian Department of Cardiovascular Imaging. Eur Heart J Cardiovasc Imaging 2016;17:589-90.

9. Kappetein AP, Head SJ, Généreux P, et al. Updated standardized endpoint definitions for transcatheter aortic valve implantation: the Valve Academic Research Consortium-2 consensus document (VARC-2). Eur J Cardiothorac Surg 2012;42:S45-S60.

10. Capodanno D, Petronio AS, Prendergast B, et al. Standardized definitions of structural deterioration and valve failure in assessing long-term durability of transcatheter and surgical aortic bioprosthetic valves: a consensus statement from the European Association of Percutaneous Cardiovascular Interventions (EAPCI) endorsed by the European Society of Cardiology (ESC) and the European Association for Cardio-Thoracic Surgery (EACTS). Eur Heart J 2017;38:3382-90.

11. Dvir D, Bourguignon T, Otto CM, et al. Standardized definition of structural valve degeneration for surgical and transcatheter bioprosthetic aortic valves. Circulation 2018;137:388-99.

12. Kuehnel RU, Hartrumpf M, Erb M, et al. Hemodynamic performance of endovascular valves as valve-in-valve in small stented bioprosthesis. Thorac Cardiovasc Surg 2017;65.

13. Zenses AS, Evin MA, Stanová V, et al. Effect of size and position of self-expanding transcatheter valve on haemodynamics following valve-in-valve procedure in small surgical bioprostheses: an in vitro study. Eurolntervention 2018;14:282-289.

14. Puri R, lung B, Cohen DJ, et al. TAVI or No TAVI: identifying patients unlikely to benefit from transcatheter aortic valve implantation. Eur Heart J 2016;37:2217-25

15. Lindman BR, Alexander KP, O'Gara PT, et al. Futility, benefit, and transcatheter aortic valve replacement. JACC Cardiovasc Interv 2014;7:707-16.

16. Lanz J, Pilgrim T. Transcatheter aortic valve replacement in patients with chronic lung disease: utile or futile? JACC Cardiovasc Interv 2017;10:2294-6.

17. Pibarot $\mathrm{P}$, Weissman NJ, Stewart WJ, et al. Incidence and sequelae of prosthesis-patient mismatch in transcatheter versus surgical valve replacement in high-risk patients with severe aortic stenosis: a PARTNER trial cohort--a analysis. J Am Coll Cardiol 2014;64:1323-34.

18. Johansen $P$, Engholt $H$, Tang $M$, et al. Fracturing mechanics before valve-in-valve therapy of small aortic bioprosthetic heart valves. Eurolntervention 2017;13:e1026-e31.

19. Nielsen-Kudsk JE, Andersen A, Therkelsen CJ, et al. High-pressure balloon fracturing of small dysfunctional Mitroflow bioprostheses facilitates transcatheter aortic valve-in-valve implantation. Eurolntervention 2017;13:e1020-e5.

20. Simonato M, Azadani AN, Webb J, et al. In vitro evaluation of implantation depth in valve-in-valve using different transcatheter heart valves. Eurolntervention 2016;12:909-17. 